\title{
WATER QUALITY INDEX FOR GROUNDWATER OF SOUTHERN PART OF BANGALORE CITY
}

\author{
Ravindra M.V ${ }^{1}$, Sharada S.A ${ }^{2}$ \\ ${ }^{I}$ Assistant Professor, Civil Engineering Department, SJCIT, Chickballapura, VTU, Belgaum \\ ${ }^{2}$ Assistant Professor, Civil Engineering Department, SJCIT, Chickballapura, VTU, Belgaum
}

\begin{abstract}
Combining different water quality parameters into one single number leads an easy interpretation of an index, thus providing an important tool for management and decision making purposes. Water quality index is a statistical index and is based on the rank order of observation. The purpose of an index is to transform the complex water quality data into information that is easily understandable and useable by the general public. As a part of research work, 14 important water viz., ${ }^{H}, \mathrm{Ec}, \mathrm{Cl}, \mathrm{Fe}, \mathrm{F}, \mathrm{SO}$, T.H, $\mathrm{Ca}, \mathrm{Mg}, \mathrm{TDS}, \mathrm{Na}, \mathrm{K}, \mathrm{Zn}, \mathrm{NO}_{3}$ were used to evaluate WQI of Southern part of Bangalore City. The water quality index number varies between (19 to122).The indices is classified as Excellent at range less than 10, Good at range 10 to 30, Medium at a range 30 to 50, Bad at a range 50 to 75, and Very Bad at a range greater than 75and the corresponding range contributed by each group is $0 \%, 18 \%, 18 \%, 28 \%$, and $36 \%$ respectively.
\end{abstract}

Keywords: WQI, Bangalore.

$* * *$

\section{INTRODUCTION}

Ground water is regarded to be one of the most valuable resources. Ground water quality is affected virtually by every activity of the society, there by making ground water protection complicated. The protection of groundwater is always cheaper than restoring already polluted aquifer. Hence the study of ground water pollution is essential. Water quality index methodology helps in the assessment of ground water pollution. Bangalore, the capital of Karnataka State, is a part of Bangalore urban district of Bangalore North and South taluks, in which the Vrishabhavathi river basin is included.The main cause of groundwater pollution is urbanization and industrialization. During the last few decades, disposal without proper treatment of sewage wastes form urban areas and of effluents from industries has been the cause of deterioration in the quality of groundwater. Water quality index is a means to summarize large amounts of water quality data into simple terms for reporting to management and the public in a consistent manner. Similar to the ultra violet (UV) index or an air quality index, it tells us whether the overall quality of water bodies poses a potential threat to various uses of water.

The WQI was first developed by Horton in the early 1970s, is basically a mathematical means of calculating a single value from multiple test results.

The index result represents the level of water quality in a given area. After Horton a number of workers all over the world developed WQI based on rating of different water quality parameters. Basically a WQI attempts to provide a mechanism for presenting a cumulatively derived, numerical expression defining a certain level of water quality (Miller et al., 1986). The different statistical approaches were followed for analyzing water quality data based on rank order of observations and factor analysis (Shoji et al., 1966,). For the evaluation of water quality, WQI was applied to river water (Ashwani Kumar et al., 2009, Rita.N.Kumar et al., 2009, N. Singkran . et al, 2010).

The objectives of the present study are:1)To estimate the WQI for the study area and to divide the area into different zones based on the extent of deterioration in the quality of groundwater.2)To suggest the different measures and uses to control the ground water pollution.3)Dividing of the area based on different activities.4)To study the implementation of groundwater quality monitoring programmes to reduce ground water contamination potential.

\section{MATERIALS AND METHODS:}

\subsection{Study Area}

Bangalore Urban and Rural area between 12 '45' N-13'45' N latitude and $7718^{\prime} \mathrm{E}-7745^{\prime} \mathrm{E}$ longitude The10 micro watersheds of Vrishabhavathi included in urban and rural areas lies between $1245^{\prime} \mathrm{N}-13$ 03' $\mathrm{N}$ latitude and $7723^{\prime} \mathrm{E}-$ 77 35' E longitudes. The Vrishabhavathi River appears in toposheets number $57 \mathrm{G} / 12,57 \mathrm{H} / 9$ and $57 \mathrm{H} / 5$. The present study area selected includes three micro watersheds covering an area of 100.8 sq. Kms located in Bangalore urban district of Bangalore North and Bangalore South taluks. The study area lies between 12 52'30" N latitude and 77 30'03” E-77 34'30" E longitude.

The entire basin extends from NNE to SSW. The three main streams carrying the industrial and domestic wastewater in the selected study area are:

1. Vrishabhvathinadi originates from peenya runs for about $14 \mathrm{~km}$ and joins the main Vrishabhvathi River. 
2. Nagarbhavithorai originates from Sanky tank runs about $18 \mathrm{Kms}$ and joins the main Vrishabhvathi River. This streambed is lined to carry the surface flow.

Khothihalla originates from Banashankari runs for about 6 $\mathrm{km}$ and joins the main Vrishabhavathiriver

\section{METHODS}

In the present study various ground water pollution-causing parameters are selected for laboratory analysis namely $\mathrm{p}^{\mathrm{H}}$, Electrical conductivity, Chloride, Iron, Fluoride, Sulphate, Total hardness, Calcium, Magnesium, Total Dissolved solids, Sodium, Potassium, Zinc, Nitrate. Water samples are collected in sampling bottles. The containers are labelled describing the date of collection, time of collection, sampling location, and conditions under which sampling are done. Analysis is done as per the standard procedure given in the standard methods (APHA).

\subsection{Calculation of Water Quality Index}

In the formulation of a Water Quality Index, the importance of the various Water quality parameters depends on the intended use of the water. The method followed for the weighted arithmetic water quality index as fallows In the first place, the more harmful a given pollutant of water, the smaller in magnitude is its standard for drinking water .So the unit weight $\mathrm{Wi}$ for the $\mathrm{i}^{\text {th }}$ parameter $\mathrm{P}_{\mathrm{i}}$ is assumed to be inversely proportional to its recommended standard $S_{i}$ $(\mathrm{i}=1,2 \ldots \mathrm{n})$ and $\mathrm{N}=$ no of parameters considered). Thus we have $\mathbf{W}_{\mathbf{i}}=\mathbf{k} / \mathbf{S}_{\mathbf{i}}=\mathbf{1} / \mathbf{S}_{\mathbf{i}}$ Where the constant of proportionality $\mathrm{K}$ has been assumed to be equal to unity for the sake of simplicity. The quality rating $q_{i}$ for the $i^{\text {th }}$ parameter $P_{i}$ is given, for all other parameters except $\mathrm{p}^{\mathrm{H}}$, by the relation

$$
Q_{i}=100\left(V_{i} / S_{i}\right)
$$

Where $\mathrm{V}_{\mathrm{i}}$ is the observed value of the $\mathrm{i}^{\text {th }}$ parameter and $\mathrm{Si}$ is its recommended standard for drinking water. For $\mathrm{p}^{\mathrm{H}}$, the quality rating $\mathrm{q}_{\mathrm{p}}{ }^{\mathrm{H}}$ can be calculated from the relation

$$
\mathrm{q}_{\mathrm{pH}}=100\left[\left(\mathrm{~V}_{\mathrm{p}}^{\mathrm{H}} \sim \mathbf{7 . 0}\right) / 1.5\right]
$$

Where $\mathrm{V}_{\mathrm{p}}{ }^{\mathrm{H}}$ is the observed value of $\mathrm{p}^{\mathrm{H}}$

Finally, the water quality index (WQI) can be calculated by taking the weighted arithmetic mean of the quality ratings $\mathrm{q}_{i}$, thus,

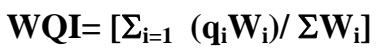

Table 1

\begin{tabular}{|l|l|l|}
\hline Parameter (Pi) & $\begin{array}{l}\text { Standard } \\
(\mathbf{S i})\end{array}$ & $\begin{array}{l}\text { Unit weight } \\
(\mathbf{W i})\end{array}$ \\
\hline PH & $6.5-8.5$ & 0.005 \\
\hline $\begin{array}{l}\text { Electrical } \\
\text { conductivity }\end{array}$ & 400 & .0025 \\
\hline Chloride & 200 & 0.005 \\
\hline Iron & 1.0 & 1.00 \\
\hline Fluoride & 1.0 & 1.00 \\
\hline
\end{tabular}

\begin{tabular}{|c|c|c|c|}
\hline $\begin{array}{l}\text { Parameter } \\
(\mathbf{P i})\end{array}$ & $\begin{array}{l}\text { observed } \\
\text { value }\end{array}$ & $\begin{array}{l}\text { quality } \\
\text { rating }\end{array}$ & Subindex(qiWi \\
\hline pH & 0.69 & 20.67 & 0.103 \\
\hline Ec & 480 & 120 & 0.3 \\
\hline Cl & 92.17 & 46 & 0.23 \\
\hline $\mathbf{F e}$ & 1 & 100 & 100 \\
\hline $\mathbf{F}$ & 0.25 & 25 & 25 \\
\hline SO4 & 28.9 & 14.45 & 0.07 \\
\hline $\begin{array}{l}\text { Total } \\
\text { hardness }\end{array}$ & 250 & 125 & 0.625 \\
\hline Ca & 154 & 205.23 & 2.66 \\
\hline Mg & 96 & 320 & 9.6 \\
\hline TDS & 400 & 80 & 0.16 \\
\hline $\mathbf{Z n}$ & 1.23 & 24.6 & 4.92 \\
\hline NO3 & 40 & 88.88 & 1.78 \\
\hline $\mathrm{Na}$ & 25 & 125 & 6.25 \\
\hline $\mathbf{K}$ & 12 & 120 & 12 \\
\hline
\end{tabular}

\begin{tabular}{|l|l|l|}
\hline Sulphate & 200 & 0.005 \\
\hline Total hardness & 200 & 0.005 \\
\hline $\begin{array}{l}\text { Calcium } \\
\text { hardness }\end{array}$ & 75 & 0.013 \\
\hline $\begin{array}{l}\text { Magnesium } \\
\text { hardness }\end{array}$ & 30 & 0.03 \\
\hline $\begin{array}{l}\text { Total dissolved } \\
\text { solids }\end{array}$ & 500 & 0.002 \\
\hline Zinc & 5.0 & 0.20 \\
\hline Nitrate & 45 & 0.02 \\
\hline Sodium & 20 & 0.05 \\
\hline Potassium & 10 & 0.1 \\
\hline$\sum W i=2.355$ & & \\
\hline
\end{tabular}

Table 2

$\sum q i W i=165.01$

WQI $=\underline{165.01}=70.07$

2.355

\subsection{Weightings and Ratings for Different}

\section{Parameters}

The 14 parameters are integrated to derive the water quality index as shown in table 3.0.Thewater quality index number varies between (19 to122).The indices is classified as Excellent at range less than 10 , Good at range 10 to 30 , Medium at a range 30 to 50 , bad at a range 50 to 75 , and very bad at a range greater than 75 and the corresponding range contributed by each group is $0 \%, 18 \%, 18 \%, 28 \%$, and $36 \%$ respectively as shown in table 3.0 
Table 3 indicates the weightings depending on water quality indices

\begin{tabular}{|l|l|l|l|l|}
\hline WQI & $\begin{array}{l}\text { Descriptor } \\
\text { Words }\end{array}$ & $\begin{array}{l}\text { Sampling Points Lies } \\
\text { In That Group }\end{array}$ & Total No & \% \\
\hline $\mathbf{7 5}$ & VERY BAD & $\begin{array}{l}2,3,5,14,15,16,22,24,3 \\
0,31,34,35,36,37,38,4\end{array}$ & & \\
\hline & $3,44,46$ & 18 & $36 \%$ \\
\hline $\mathbf{5 0}$ to 75 & BAD & $1,4,11,23,25,28,29,40$, & & \\
$41,42,45,47,48,50$ & 14 & $28 \%$ \\
\hline $\mathbf{3 0}$ to50 & MEDIUM & $\begin{array}{l}8,9,13,17,26,32,33,41, \\
49\end{array}$ & & \\
\hline $\mathbf{1 0}$ to 30 & GOOD & $6,7,10,12,18,19,20,21$, & & $18 \%$ \\
\hline & 27 & 9 & $18 \%$ \\
\hline $\mathbf{1 0}$ & $\begin{array}{l}\text { EXCELLEN } \\
\text { T }\end{array}$ & NONE & NONE & $0 \%$ \\
\hline
\end{tabular}

\section{DISCUSSION}

- At present settlement area is located in very bad and bad area requires more precautionary measures because small quantity of contaminants entry into ground in this region in this causes ground water pollution in large scale.

- At present very bad area located near the earthen sewage drains are passing mainly near cholurpalya

\section{CONCLUSION AND RECOMMENDATIONS}

From the present scenario it is quite evident that our dependency on ground water is going to with every passing day. In the view of this growing demand deterioration in the quality of ground water there is an urgent need to take up effective measures for conservation management and augmentation of ground water resources a comprencive ground water management plan involving ground water scientists, city planners, land use exports, environmentalists and general public should be drawn.

The following steps should facilitate this

1. More observation station for water level and quality monitoring should be established.

2. Setting of ground water obstruction structures should be scientific and Proper care should be taken to keep it away from the influence of waste disposal sites.

3. Artificial recharge schemes should be made popular. this can be done by popularizing roof tap rain water harvesting methods to achieving this building codes of the city may be suitably revised to make this mandatory for all new constructions.

4. Disposal of municipal waste should be managed properly apart from proper treatment of sewage.

5. Mass awareness programs to educate public should be arranged by involving NGO groups and through electronic media.

\section{ACKNOWLEDGEMENTS}

I acknowledge my regards to the Department of Civil Engineering, S.J.C.Institute of Technology, Chickballapur, Karnataka State, for encouraging me by allowing to do research work.

\section{REFERENCES}

[1] Ashwani Kumar and AnishDua, 2009, Water quality index for assessment of water quality of River Ravi at Madhopur Global Journal of Environmental Sciences Vol. 8 No.1, 2009: 49-57.

[2] CPHEEO (Central Public Health Environmental Engineering Organization), 1991. Manual of water supply and treatment, Ministry of Urban Development, New Delhi.

[3] APHA;"Standard Methods for the Examination of water and wastewater; Sixteenth edition; 1995

[4] Dr.Bassappa Reddy. M "Ground water resources and Management Strategies for the $21^{\text {st }}$ century, Government of Karnataka; Department of mines and geology, 1994

[5] CGWB "Workshop on Ground Water Monitoring Development and management" Ministry of water resources, South West Region; Bangalore; 2000

[6] Dr Kottaiah. B "Environmental engineering lab manual" Chroatar First Edition; 1994

[7] KSPCB" Hand Book on Environmental Laws and Guide Lines "Karnataka Pollution Control Board Officer's Association" First edition, 2000

[8] NEERI; "Water and wastewater Analysis manual" National Environmental Engineering Research Institute, Nagpur, 1988

[9] Pramod Kumar U.S. "To study the impact of wastewater and ground water Quality in Vrishabhavathi basin; M.E.Dissertation; Bangalore University 2000

[10] Pradeep K. Jain; "Assessment of Ground water quality in Singhari river Basin of central India" 